\title{
Inter college adolescents career preferences in urban Kanpur of Uttar Pradesh
}

\author{
MEENAKSHI SINGH AND SHIKHA SHAKYA
}

Received: 02.12.2015; Revised: 04.05.2016; Accepted: 15.05.2016

See end of the paper for authors' affiliations MEENAKSHI SINGH Institute of Home Science, Bundelkhand University, JHANSI (U.P.) INDIA

Email : singhmeenu71@gmail.com
- ABSTRACT : Present study was conducted in Kanpur city of UP state on 300 adolescents (147 boys and 153 girls) randomly selected from 6 intermediate colleges to assess their carrier preferences (science and technology-ST, commerce and management-CM, tourism and hospitality-TH, mass media and journalism-MMJ, artistic and designing-AD, medical-M, agriculture-AG, defense-D, law and order-LO and education-E) using Standard Carrier Test. Data revealed that adolescents were in age group between 14-17 years. Higher number of respondents belonged (each $23.66 \%$ ) to business and service class families, while lowest number of adolescents belonged to families working in factories (16.66\%). About 47 per cent of adolescent's families had income less than Rs. 5000/-month and lowest number of respondents (20.0\%) had family income between Rs. 5000 to 10000/-month. Data further revealed that ST was the most preferred carrier of adolescents (64) and AG as least preferred carrier (0). Girls preferred $\mathrm{M}, \mathrm{MMJ}$ and $\mathrm{AD}$ over boys while later have more preference to ST and CM than former. There was change in preference of adolescents for carrier over different month's period. It is evident from the results that ST and M is the most preferred carrier, while AG and D are the least preferred carriers among adolescents. Preference of adolescents to carrier also changes with time.

KEY WORDS: Adolescents, Carrier preferences, Inter college, Social variables

- HOW TO CITE THIS PAPER : Singh, Meenakshi and Shakya, Shikha (2016). Inter college adolescents career preferences in urban Kanpur of Uttar Pradesh. Asian J. Home Sci., 11 (1) : 166-170, DOI: 10.15740/ HAS/AJHS/11.1/166-170. 